\title{
Preliminary Study of Potential Herbal Tea, Acalypha indica and Comparison with Domestic Tea in Malaysia Market
}

\author{
Nor Syahiran Zahidin ${ }^{1}$, Razauden Mohamed Zulkifli ${ }^{1}$, Ida Idayu Muhamad ${ }^{2,3}$, Harisun Ya'akob ${ }^{2,4}$, \\ Hadi Nur ${ }^{5}$, Amir Husni Mohd Shariff ${ }^{6}$, Syafiqah Saidin ${ }^{1,3, *}$ \\ ${ }^{1}$ Faculty of Biosciences \& Medical Engineering, Universiti Teknologi Malaysia, Malaysia \\ ${ }^{2}$ Faculty of Chemical and Energy Engineering, Universiti Teknologi Malaysia, Malaysia \\ ${ }^{3}$ IJN-UTM Cardio Centre, Universiti Teknologi Malaysia, Malaysia \\ ${ }^{4}$ Institute of Bioproduct Development (IBD), Universiti Teknologi Malaysia, Malaysia \\ ${ }^{5}$ Centre for Sustainable Nanomaterials, Ibnu Sina Institute for Scientific and Industrial Research, \\ Universiti Teknologi Malaysia, Malaysia \\ ${ }^{6}$ Faculty of Food Science and Nutrition, Universiti Malaysia Sabah, Malaysia
}

Copyright $\bigcirc 2018$ by authors, all rights reserved. Authors agree that this article remains permanently open access under the terms of the Creative Commons Attribution License 4.0 International License

\begin{abstract}
Tea is commonly served in Malaysian dining culture. Most of commercialized tea is made of Camellia sinensis that produces sweet aromatic smell. However, there are plenty of herb species in Malaysia that remain unknown to be used as tea while possess therapeutic effects. Acalypha indica is one of the herb species with sweet aromatic smell that has been traditionally consumed as healthy drink. In this study, the antioxidant activities of all plant parts of Acalypha indica was determined in terms of total phenolic, tannin and flavonoid contents, 1,1-Diphenyl-1- picrylhydrazyl (DPPH) assay, ferric reducing power (FRAP) and total cyanogenic glycoside content by comparing the measurements with two commercialized tea made of Camellia sinensis (P1 and P2). The phenolic content, tannin content and the FRAP values of Acalypha indica was lower than the $\mathrm{P} 1$ and $\mathrm{P} 2$. While, higher flavonoid content $(24.33 \pm 2.96 \mathrm{mgQE} / \mathrm{g})$ and DPPH value $\left(0.089 \pm 0.003 \mathrm{mg} / \mathrm{mL}, \mathrm{IC}_{50}\right)$ were recorded on the Acalypha indica. The high antioxidant activity of Acalypha indica was attributed by the high flavonoid content in the plant that might be useful for therapeutic purpose. Besides, it is also safe to be consumed as tea as there was no detection of cyanogenic. However, further study is necessary to clarify the cyanogenic content and to confirm the volatile compound in the plant.
\end{abstract}

Keywords Acalypha indica, Tea, Antioxidant Drink

\section{Introduction}

Tea is a beverage served with or without sweetener such as sugar, creamer or milk. It is a low-cost drink, affordable by most people compared to other beverages. Tea is synonyms with a shrub plant species called Camellia sinensis. It is prepared by immersing dried plant leaves in hot water. Drinking tea has become part of Malaysian culture as it is commonly found and served at home, restaurants, events and feasts. Tea leaves are packed in various packaging form which are available in groceries as different brands, flavor and prices for customer selection. People are enjoying tea due to its delicious flavor and fragrant aroma produced by its leaves. Due to long-term demand from Malaysian consumers, the government and the private sectors are developing several tea plantations for commercialization purpose, as located in Kundasang, Sabah and Cameron Highland, Pahang [1]. Nowadays, Malaysia has become one of the regular countries in generating income for local and international supplies.

However, there are still plenty of plants that remain unknown which can be utilized as tea. Since Malaysia is a tropical rainforest climate country, multiple resources of plant species are growing in this region. These plants have their own commercial values either as food sources, medicinal supplies, or both. Researchers are working diligently to identify any possible plant that is useful for both applications. Several plants located, not only in deep forest but also near to our settlement, presented as weed, moss, or fungi have potential to be adopted as tea. Among the plants, some of them have aromatic fragrant that suitable for daily consumption. Therefore, this paper aimed to emphasize a weed plant species called Acalypha indica that has potential to be used as a fragrant herbal drink.

Acalypha indica is a shrub green plant grows at many 
areas around the world, especially close to the equatorial region [2]. In Malaysia, Acalypha indica is mentioned as Pokok Kucing Galak, or Ceka Emas [3]. Only few communities aware about this plant where most of them are elder generation and cat keeper. The elder generation consumes this plant as a health supplement for energy booster and asthma treatment. Meanwhile, the cat keepers apply this plant root as a natural health remedy for their cat. Naturally, cats are more attracted to the root part of the plant compared to the others due to the composition of phytocompounds that stimulating cat sensory [3]. Few peoples in Malaysia consume this plant as a herb and healthy drink while the Indian communities massively use this plant as Ayurveda medicine [4]. Besides, Acalypha indica has many therapeutic effects that are beneficial for human health [5]. However, people are not aware on its fragrance aroma, especially after the drying process of its leaves.

Acalypha indica has good antioxidant activity for several treatments due to its free radical scavenging activity [6]. It has moderate total phenolic content compared to the domestic teas and rich with flavonoids which assists as an additional value in treating diseases. In this study, a domestic tea products of Camellia sinensis (available in Malaysia market) was compared with all plant parts of Acalypha indica. Preliminary data related to antioxidant activities such as total phenolic content (TPC), total tannin content (TTC), total flavonoid content (TFC), 1,1-Diphenyl-1-picryl hydrazyl (DPPH) assay, ferric reducing power (FRAP) and total cyanogenic glycoside content were presented and discussed.

\section{Materials and Methods}

\subsection{Sample Preparation}

Acalypha indica herb was cultivated and harvested in a plot at Faculty of Biosciences and Medical Engineering, Universiti Teknologi Malaysia. The fresh of all plant parts were collected, washed using tap water and dried at room temperature to remove excessive water. The all plant parts were intensively dried in a drying oven (Universal Oven UF110, Memmert, German) at $60^{\circ} \mathrm{C}$ for 24 hours. It was then pulverized using a blender and sieved using a sieve shaker (M200 Miniature Laboratory Sieve Shaker, Endecotts, UK) to obtain uniform plant powders. The powders with less than $1 \mathrm{~mm}$ mesh size were collected and extracted by a soxhlet extractor [7]. Distilled water was used during the extraction process as the final product is intended for drinking purpose. The extracted solution was dried slowly in a drying oven to separate water and crude extract for 8 hours at $60^{\circ} \mathrm{C}$. Another two tea products of Camellia sinensis were purchased at local groceries shop. Both teas were extracted using similar previous method [7] and known as P1 and P2.

\subsection{Antioxidant Analyses}

\subsubsection{Total Phenolic Content (TPC)}

The amount of TPC of extracted teas was measured using Folin-Ciocalteu reagent method from Sen et al. [8] with a slight modification. A total of $30 \mu \mathrm{L}$ extract of each sample with $1 \mathrm{mg} / \mathrm{mL}$ concentration was prepared in 96 well plates. Then, $120 \mu \mathrm{L}$ of $10 \%$ Folin-Ciocalteu (v/v) and $150 \mathrm{uL}$ of $2 \%$ sodium carbonate $(\mathrm{w} / \mathrm{v})$ were added into the extraction. The mixture was incubated for 5 minutes at room temperature. The optical absorbance of the mixture was recorded using a microplate reader (Epoch Microplate Spectrophotometer, BioTek, USA) at a wavelength of 765 $\mathrm{nm}$. The calibration curve for this assay was plotted using gallic acid as the standard at a range between 0.0 and 0.5 $\mathrm{mg} / \mathrm{mL}$.

\subsubsection{Total Tannin Content (TTC)}

For the measurement of TTC, $100 \mathrm{mg}$ of insoluble polyvinylpolypyrrolidone (PVPP) was added in $5 \mathrm{mg} / \mathrm{mL}$ of extract solution as described by Singh et al. [9]. The mixture was roughly shaked and vortexed for optimum homogeneity. After that, the mixture was incubated at $4^{\circ} \mathrm{C}$ for 15 minutes and later centrifuged for 10 minutes at $3000 \mathrm{rpm}$. An aliquot of supernatant was collected to be tested with a phenolic content assay. The TTC was calculated according to the initial total phenolic content before insoluble PVPP was loaded, and later subtracted with the remained total phenolic content. The tannin in the mixture was precipitated with the PVPP and then separated into two layers after the centrifuging process. The non-tannin phenolic content that remained in the supernatant layer was finally measured.

\subsubsection{Total Flavonoid Content (TFC)}

Accordingly, $25 \mu \mathrm{L}$ of $5 \mathrm{mg} / \mathrm{mL}$ extract was mixed with $153 \mu \mathrm{L}$ water which contained $7.5 \mu \mathrm{L}$ of $5 \%$ sodium nitrite. After 6 minutes, $15 \mu \mathrm{L}$ of $10 \%$ aluminum chloride was added to the mixture for 15 minutes, followed by the addition of $50 \mu \mathrm{L}$ of $1 \mathrm{M}$ sodium hydroxide. The mixture was aged at room temperature for 10 minutes to achieve stable reaction. Finally, the optical absorbance of the mixture was recorded using a microplate reader (Epoch Microplate Spectrophotometer, BioTek, USA) at $415 \mathrm{~nm}$ wavelength. Quercetin was used as the standard of calibration curve ranged from 0.0 to $1.0 \mathrm{mg} / \mathrm{mL}$ concentration. This method was slightly modified from the study reported by Chang et al. [10].

\subsubsection{DPPH Antioxidant Scavenging Activity}

The free radical scavenging activity of the extract was performed in a 96 well plate with gradually decreasing concentration, starting from $1 \mathrm{mg} / \mathrm{mL}$ to $0.007 \mathrm{mg} / \mathrm{mL}$ by using distilled water as a working medium. A total of 100 $\mu \mathrm{L}$ of the extract was mixed with $100 \mu \mathrm{L}$ of $0.004 \%$ DPPH solution which diluted in methanol. The optical 
absorbance of the mixture was then recorded at a wavelength of $517 \mathrm{~nm}$. The percentage of scavenging activity of the samples was estimated by using Equation (1). Plain distilled water was used as the blank negative control. A mixture without the DPPH assay was measured as the background color by deducting the value from the background color to calculate the final absorbance value for the antioxidant scavenging activity.

$$
\mathrm{I} \%=[(\text { Acontrol }- \text { Asample }) / \text { Acontrol }] \times 100
$$

\subsubsection{Ferric Reducing Power (FRAP) Capacity}

The FRAP assay was performed according to a method evaluated by Khalil et al. [11]. The FRAP reagent was prepared using $0.3 \mathrm{M}$ acetate buffer $(3.6 \mathrm{pH})$ and $0.01 \mathrm{M}$ 2,4,6-Tri(2-pyridyl)-s-triazine (TPTZ), diluted in $0.04 \mathrm{M}$ hydrochloric acid. A total of $35 \mu \mathrm{L}$ of $5 \mathrm{mg} / \mathrm{mL}$ extract was added into $265 \mu \mathrm{L}$ of FRAP reagent and its optical absorbance was measured at $593 \mathrm{~nm}$ wavelength. The standard of calibration curve was plotted using ferrous sulfate, ranged from 0.0 to $0.4 \mathrm{mg} / \mathrm{mL}$. The reducing power of samples was measured by interpolating the absorbance value with the ferrous sulfate equivalent value.

\subsubsection{Total Cyanogenic Glycoside Content}

The method by Sarkiyayi et al. [12] was referred in measuring the total cyanogenic glycoside content of the extract. This test was performed only on the Acalypha indica extract due to the presence of cyanogenic glycoside as projected by other studies $[13,14]$. An extraction of 60 $\mu \mathrm{L}(1 \mathrm{mg} / \mathrm{mL}$ was diluted in distilled water $)$ was mixed with $240 \mu \mathrm{L}$ alkaline picrate solution. The optical absorbance of the mixture was recorded at $490 \mathrm{~nm}$ wavelength. Alkaline picrate solution was then prepared by adding $1 \mathrm{~g}$ of picrate acid and $5 \mathrm{~g}$ of sodium hydroxide in $200 \mathrm{~mL}$ distilled water. Sodium cyanide was chosen as the standard of calibration curve ranged from 0.0 to 1.0 $\mathrm{mg} / \mathrm{mL}$.

\subsubsection{Statistical Test}

All samples were prepared in triplicate for statistical analysis. The data were presented as mean with standard error mean (SEM) and analyzed consecutively, through the normality test, homogeneity test and one-way analysis of variance (ANOVA), followed by Bonferroni and Dunnett's T3 post-hoc test. The software used in this analysis was IBM SPSS Statistic 23 (IBM, USA). A level of $p<0.05$ was set as the criterion for statistical significance.

\section{Results and Discussion}

\subsection{Result}

Data of the TPC, TTC, TFC, DPPH scavenging activity and FRAP were presented in Table 1 and Table 2. For the
TPC, the equivalent total content was referred to gallic acid calibration curve $\left(\mathrm{Y}=6.478 \mathrm{x}+0.019, \mathrm{R}^{2}=0.9996\right)$. The TPC inside the P1 and P2 were greater than the Acalypha indica where there was no significance different between the $\mathrm{P} 1$ and $\mathrm{P} 2$. This result indicates that both tea products made from Camellia sinensis, sold in the local market, have similar amount of phenolic content.

The TTC in the P1 and P2 also was found higher than the Acalypha indica. Tannin is a large structure of polyphenol, partly expressed from the TPC. Most TPC of tea were consisted of $86 \%$ tannin content. However, tannin inside the P2 was significantly higher than the P1 although both products were coming from the same species. Such factor is plausible, fact there are many hybrid tea plants and cultivars evolve due to weather, temperature and location that affect its phytocompound content [1].

For the TFC, the Acalypha indica has more flavonoids than the P1 and P2. The assay used in this study was not able to detect the flavonoid content inside both tea products at the similar concentration with Acalypha indica. However, there is a study demonstrated that, through HPLC analysis, only catechins flavonoid was presence including its gallates in tea extract [15]. In contrast with the used assay, there was no flavonoid presence. The extract concentration of $\mathrm{P} 1$ and $\mathrm{P} 2$, used in the experiment could be too low cause the absence of flavonoid content, compared to the Acalpha indica. The flavonoids derived from the Acalypha indica are comprised of chrysin, hesperetin, quercetin, kempferol, naringin and naringenin [16-18].

Table 1. Comparison of total phytocompound content between Acalypha indica (A.I) and two other tea products (P1 and P2) sold in Malaysia

\begin{tabular}{|c|c|c|c|}
\hline & TPC (mgGAE/g) & TTC (mgGAE/g) & TFC (mgQE/g) \\
\hline A.I & $1016.73 \pm 41.10^{\mathrm{a}}$ & $694.00 \pm 6.74^{\mathrm{a}}$ & $24.33 \pm 2.96^{*}$ \\
\hline P1 & $2653.73 \pm 51.60^{\mathrm{b}}$ & $2306.00 \pm 1.00^{\mathrm{b}}$ & $<0.001^{*}$ \\
\hline P2 & $2765.07 \pm 51.09^{\mathrm{b}}$ & $2412.00 \pm 3.93^{\mathrm{c}}$ & $<0.001^{*}$ \\
\hline
\end{tabular}

A.I $=$ Acalypha indica $; \mathrm{P} 1=$ Product $1 ; \mathrm{P} 2=$ Product 2. Values were expressed as mean \pm SEM $(n=3)$; One-way ANOVA with Bonferroni and Dunnett's T3 post-hoc was applied. a $\mathrm{b}_{\mathrm{c}}=$ each group has significance different with control at $p<0.05 ; *=$ No statistical analysis was conducted due to no output data produced from assay

The antioxidant activity of the Acalypha indica was recorded to be lower than both tea products by comparing the DPPH values of the Acalypha indica with P1 and P2. The antioxidant activity of the extracts was measured by using half maximal inhibitory concentration $\left(\mathrm{IC}_{50}\right)$. The $\mathrm{IC}_{50}$ value for both tea products was $0.005 \mathrm{mg} / \mathrm{mL}$ compared to the Acalypha indica with $0.089 \mathrm{mg} / \mathrm{mL}$. Tea made of Camellia sinensis possessed an antioxidant activity of 19 times stronger than the Acalypha indica, and it was comparable to the Vitamin $C$ which was used as the positive control in this assay. The tannin content in both tea products is expected to be the factor for the measurement of high antioxidant activity since the 
flavonoid content in both teas was too low. While the antioxidant activity of the Acalypha indica is expected to come from the high flavonoid content and supported by some phenolic compound. However, the Acalypha indica is still being considered to possess medium antioxidant activity because the $\mathrm{IC}_{50}$ value was below than 0.1 $\mathrm{mg} / \mathrm{mL}$.

Table 2. Comparison of DPPH and FRAP between Acalypha indica and two other tea products sold in Malaysia

\begin{tabular}{|c|c|c|}
\hline & DPPH $\left(\mathrm{IC}_{50}\right) \mathrm{mg} / \mathrm{ml}$ & FRAP $\left(\mathrm{mgFeSO}_{4} / \mathrm{g}\right)$ \\
\hline A.I & $0.089 \pm 0.003^{\mathrm{a}}$ & $44.53 \pm 0.76^{\mathrm{a}}$ \\
\hline P1 & $0.005 \pm 0.001^{\mathrm{b}}$ & $72.95 \pm 7.57^{\mathrm{b}}$ \\
\hline P2 & $0.005 \pm 0.001^{\mathrm{b}}$ & $65.72 \pm 1.08^{\mathrm{b}}$ \\
\hline Vitamin C & $0.003 \pm 0.001^{\mathrm{b}}$ & - \\
\hline
\end{tabular}

A.I $=$ Acalypha indica, $\mathrm{P} 1=$ Product $1, \mathrm{P} 2=$ Product 2 . Values were expressed as mean \pm SEM $(\mathrm{n}=3)$; One-way ANOVA with Bonferroni and Dunnett's T3 post-hoc was applied. ${ }^{\mathrm{a}} \mathrm{b} \mathrm{c}=$ each group has significance difference with control at $p<0.05$

The ability of the sample to reduce free radical compound was measured according to the FRAP assay. The $\mathrm{Fe}^{3+}$ ions from the FRAP reagent was reduced to the $\mathrm{Fe}^{2+}$ ions when an antioxidant compound was introduced during the reaction. The capacity of electron reduction from both tea products was significantly higher than the Acalypha indica. The FRAP value for the Acalypha indica was $44.53 \pm 0.76 \mathrm{mg} \mathrm{FeSO} 4 / \mathrm{g}$ while for the P1 and P2, the values were $72.95 \pm 7.57 \mathrm{mg} \mathrm{FeSO} 4 / \mathrm{g}$ and $65.72 \pm 1.08 \mathrm{mg}$ FeSO4/g, respectively. The P1 and P2 were not statistically different to each other but obviously different to the Acalypha indica.

Finally, the results of total cyanogenic glycoside content showed no detection of cyanogenic glycoside in the Acalypha indica. However, since several studies revealed the presence of cyanogenic compound in the plant $[13,14]$, it is crucial to justify the result with a more sensitive test to clarify the non-existence of cyanogenic glycoside in the plant extracted by water. The previous studies which detected cyanogenic compound in the plant were using ethanol or methanol as a solvent extractor during the extraction process. There is a possibility that, a very low amount of cyanogenic compound presence in the water extraction but it was not detected through the assay.

The normality tests showed that all data were normal except for the P1, TTC and DPPH. Data of the TPC and TTC were homogeneous while data for the DPPH and the FRAP were not homogeneous. Table 1 and Table 2 shows the significance of one-way analysis of variance (ANOVA) using Bonferroni for the homogeneous data and Dunnett's T3 for the non-homogenous data.

\subsection{Discussion}

This paper only provides preliminary data related to the anti-oxidant activity of the tea extracts as these plants have potential to be used as herbal drink. From Table 2, the Acalypha indica is considered to has moderate antioxidant activity based on the DPPH and FRAP values compared to the available tea products. The phenolic, tannin and flavonoid from the Acalypha indica act as a responsible phytocompounds for the antioxidant activity and other therapeutic activities. Both tea products have high quantity phenolic and tannin contents that respond with antioxidant activity, but less flavonoid compound for other therapeutic function. By drinking tea made of Acalypha indica, the person will get both benefits of antioxidant and therapeutic effects [19-21].

The interest of this study is to support the suggestion in making this plant as an alternative tea drink where its sweet smell can be an attraction for meal consumption. Therefore, it is necessary to further investigate the antioxidant activities of each plant part and to assess the volatile compounds which could be derived from Acalypha indica. Nevertheless, the people can enjoy this herbal tea drink at minimal cost and sufficient antioxidant value. People from the rural area can also use this plant as a drink replacement. However, the measurement of sweet aromatic smell mimicking the tea aroma from the Acalypha indica is not covered in this paper.

An awareness when consuming Acalypha indica is necessary since this plant has some cyanogenic glycoside that is harmful to the human body at a consumption of high concentration. However, this fact is neglected as communities in India, consume this plant, daily, as a green leafy vegetable [2]. While in Malaysia, some people drink this plant extraction as a health supplement with precaution on its toxicity. Further study related to this issue should be bold as a prevention for later complication.

\section{Conclusions}

Acalypha indica has a potential to be used as an alternative herbal tea drink based on its antioxidant activity compared to the domestic tea products. The higher content of flavonoids in the Acalypha indica could become an exclusive value compared to the other teas. Besides, the flavonoids in the Acalypha indica are beneficial for other therapeutic applications. Further study related to this plant toxicity need to be done accordingly to further investigate its human compatibility property.

\section{Acknowledgements}

This work was financed by research university grant (RUG), Universiti Teknologi Malaysia Q. J130000.2545.12H84 from Ministry of Higher Education (MOHE), Malaysia. 


\section{REFERENCES}

[1] R. Verwoerd, V. L. Facenda. Discovering tea in Malaysia. Tea and Coffee Trade Journal.

[2] Schmelzer G. H., Acalypha indica L, Online available from http://database.prota.org/PROTAhtml/Acalypha\%20indica En.htm

[3] G. Andries. Efek neuroterapi ekstrak air akar Acalypha Indica Linn. dosis 15 dan $20 \mathrm{mg}$ secara eks vivo pada persambungan saraf-otot gastroknemius katak Bufo melanostictus Schneider, in Fakultas Kedokteran, Universitas Indonesia, Indonesia, 2009.

[4] G. Ranju, S. Niranjan, P. S. Kumar, P. V. Kumar, P. S. Kumar. In vitro anthelmintic activity of Acalypha indicaleaves extracts, International Journal of Research in Ayurveda and Pharmacology, Vol.2, No.1, 247-249.

[5] B. Dineshkumar, S. P. Bhuvaneshwaran, A. Mitra. Phyto-pharmacology of Acalypha Indica: A review, International Journal of BioSciences, Alternative and Holistic Medicine, Vol.1, No.2, 27-32.

[6] D. Sanseera, W. Niwatananun, B. Liawruangrath, S. Liangruangrath, A. Baramee, K. Trisuwan, S. G. Pyne. Antioxidant and anticancer activities from aerial parts of Acalypha indica Linn., Chiang Mai University Journal of Natural Sciences, Vol.11, No.2, 157-168.

[7] R. Jayaprakasam, T. K. Ravi. Evaluation of anti arthritic activity of the root extract of Acalypha indica Linn. using in vitro techniques, International Journal of Phytopharmacy, Vol.2, No.6, 169-173.

[8] S. Sen, B. De, N. Devanna, R. Chakraborty. Total phenolic, total flavonoid content, and antioxidant capacity of the leaves of Meyna spinosa Roxb., an Indian medicinal plant, Chinese Journal of Natural Medicines, Vol.11, No. 2, 149157.

[9] R. Singh, P. K. Verma, G. Singh. Total phenolic, flavonoids and tannin contents in different extracts of Artemisia absinthium, Journal of Intercultural Ethnopharmacology, Vol.1, No.2, 101-104.

[10] C. L. Chang, C. S. Lin, G. H. Lai. Phytochemical characteristics, free radical scavenging activities, and neuroprotection of five medicinal plant extracts, Evidence-Based Complementary and Alternative Medicine, No. $984295,1-8$.
[11] M. Khalil, N. Alam, M. Moniruzzaman, S. A. Sulaiman, S. H. Gan. Phenolic acid composition and antioxidant properties of Malaysian honeys, Journal of Food Science, Vol.76, No.6, C921-C928.

[12] S. Sarkiyayi, T. Agar. Comparative analysis on the nutritional and anti-nutritional contents of the sweet and bitter cassava varieties, Advance Journal of Food Science and Technology, Vol.2, No.6, 328-334.

[13] A. Nahrstedt, J. D. Kant, V. Wray. Acalyphin, a cyanogenic glucoside from Acalypha indica, Phytochemistry, Vol.21, No.1, 101-105.

[14] M. Hungeling, M. Lechtenberg, F. R Fronczek, A. Nahrsted. Cyanogenic and non-cyanogenic pyridone glucosides from Acalypha indica (Euphorbiaceae), Phytochemistry, Vol.70, No.2, 270-277.

[15] L. Yao, Y. Jiang, N. Datta, R. Singanusong, X. Liu, J. Duan, K. Raymont, A. Lisle, Y. Xu. HPLC analyses of flavanols and phenolic acids in the fresh young shoots of tea (Camellia sinensis) grown in Australia, Food Chemistry, Vol.84 No.2, 253-263.

[16] S. Hiremath, K. Rudresh, S. Badami. Flavonoids of Acalypha indica Linn., Indian Journal of Heterocyclic Chemistry, Vol.8, No.2, 163-164.

[17] A. Nahrstedt, M. Hungeling, F. Petereit. Flavonoids from Acalypha indica, Fitoterapia, Vol.77, No.6, 484-486.

[18] Y. T. Ma, J. I. Chuang, J. H. Lin, F. L. Hsu. Phenolics from Acalypha indica, Journal of the Chinese Chemical Society, Vol.44, No.5, 499-502.

[19] S. Rajasekaran, R. Anandan, K. Nishad. Antihyperlipidemic activity of Acalypha indica Linn on atherogenic diet induced hyperlipidemia, International Journal of Pharmacy and Pharmaceutical Sciences, Vol.5, No.4, 699-701.

[20] N. N. Baharum. Analysis of Acalypha Indica extracts for antioxidant and antibacterial activities, in Department of Biosciences and Health Sciences, Universiti Teknologi Malaysia, Malaysia, 2015.

[21] E. H. Purwaningsih, N. Ibrahim, H. Zain, A. Tedjo. Neuro-protection and neuro-therapy effects of Acalypha indica Linn. water extract ex vivo on Musculus gastrocnemius frog. MAKARA of Health Series, Vol.12, No. 2, 70-75. 